\title{
Computed tomographic evaluation of mediastinal masses/ lesions with contrast enhancement and correlation with pathological diagnosis - a study of 120 cases
}

\author{
Harmeet Kaur ${ }^{1}$, Punit Tiwari², Pankaj Dugg ${ }^{3}$, Jasmine Ghuman ${ }^{4}$, Pankaj Shivhare ${ }^{5}$, Raghbir S \\ $\mathrm{Mehmi}^{6}$
}

1. Department of Radiodiagnosis, DMCH, Ludhiana, India. 2. Department of Orthopaedics, Govt. Medical College, Patiala, India. 3. Department of Surgery, AlIMS, New Delhi, India. 4. Department of Medicine, MGMMC, Aurangabad, India. 5. Department of Neurosurgery, AlIMS, New Delhi, India. 6. Department of Medicine, Govt. Medical College, Patiala, India.

Correspondence: Pankaj Dugg. Address: VPO Nussi, Jalandhar, Punjab, India. E-mail: pankajdugg84@gmail.com

Received: April 17, 2014

DOI : $10.5430 / j b g c . v 4 n 3 p 28$
Accepted: June 24, 2014

URL: http://dx.doi.org/10.5430/jbgc.v4n3p28

\section{Abstract}

Objective: The study was conducted to diagnose the mediastinal lesions/masses by computed tomographic on contrast enhanced scans and findings were compared with pathological diagnosis wherever possible.

Methods: Contrast Enhanced Computed Tomography (CECT) of chest done in supine position in inspiration with 60 to $120 \mathrm{ml}$ of $300 \mathrm{mg} / \mathrm{ml}$ of nonionic iodinated contrast and images were viewed in lung window (level $700 \mathrm{HU}$; width 1,500 HU), mediastinal window (level $30 \mathrm{HU}-50 \mathrm{HU}$; width $350 \mathrm{HU}-500 \mathrm{HU}$ ) and bone window (level 2,400 HU; width 200 $\mathrm{HU})$.

Results: The most common compartment to be involved was anterior mediastinum (38.3\%) followed by posterior (16.7\%), middle (13.3\%) and superior mediastinum (11.7\%) in that order. Predominant lesions were benign. The commonest lesion was tubercular lymphadenopathy (15\%). Thymic masses and metastatic lymph node (26\% each) were the most common mediastinal lesions in the anterior mediastinal compartment. Neural tumors (50\%), esophageal carcinoma (37.5\%) and thyroid masses (85.7\%) were the common lesions in posterior, middle and superior mediastinal compartments respectively. Ascending aortic aneurysm was the predominant vascular lesion in our study (6.7\%). Out of total 120 cases, 102 cases were histologically verified, six cases with hiatal hernia were confirmed with endoscopy while in 12 cases of vascular origin, and definitive diagnosis was established with Computed tomography (CT) scan alone.

Conclusions: CT scan can distinguish specific tissue densities and its ability to display mediastinum in axial plane makes it a useful technique in the evaluation of a mediastinal mass.

\section{Key words}

Computed tomography, Mediastinum, Mass, Tuberculosis 


\section{I ntroduction}

Computed tomography (CT) is an imaging method employing tomography created by computer processing. Digital geometry processing is used to generate a three-dimensional image of the inside of an object from a large series of twodimensional X-ray images taken around a single axis of rotation.

The mediastinum is an extra pleural space within the thorax between the two pleural spaces. It extends from the sternum anteriorly to the vertebral column posteriorly. The upper limit is formed by the thoracic inlet and the lower limit by the diaphragm. An imaginary plane extends from the sternal angle to the lower border of the fourth dorsal vertebra dividing the mediastinum into superior and inferior divisions. The inferior mediastinum is subdivided by the heart into anterior, middle and posterior mediastinum ${ }^{[1]}$. Localization of mediastinal masses to one of these divisions can facilitate their differential diagnosis on conventional radiographs.

On CT, however, it is more appropriate to base the differential diagnosis of a mediastinal mass on direct observation of the tissue or structure from which the mass is arising (e.g., lymph nodes, veins, arteries, thymus and thyroid) rather than its location. The multitude of diseases affecting the mediastinum varies considerably, comprising of tumours (benign to extremely malignant), cysts, vascular anomalies, lymph node masses, mediastinitis, mediastinal fibrosis and pneumomediastinum. CT clearly demonstrates the malleable nature of the cysts, which change their shape with respect to change in position from prone to decubitus ${ }^{[2]}$.

CT gives clear delineation of lesions and distinguishes them better from normal structures. CT clearly demonstrates mediastinal invasion based on the following criteria: (1) confluence of tumor with mediastinum; (2) angle more than 90 degrees between the mass and mediastinal vessels or pericardium; (3) indentation of border between the mass and vessel with absence of mediastinal fat plane; (4) thickened wall of proximal end of main stem bronchus ${ }^{[3]}$. In correlation with clinical data, it is more accurate in suggesting whether lesions are benign or malignant ${ }^{[4]}$.

CT allows the differentiation of a mediastinal mass from normal mediastinal structures, characterization of its density, its localization and discrimination of vascular and avascular lesions ${ }^{[5]}$. Coexisting lung abnormalities and calcification within the lesions are better appreciated on CT. It is useful for distinguishing vascular variants or benign pathologies of mediastinum such as lipomatosis, from true pathological conditions. CT scanning can differentiate vascular from avascular causes of mediastinal widening ${ }^{[6]}$. Mediastinal lymph node abnormalities can be seen in any mediastinal compartment, although they most commonly involve middle mediastinal regions ${ }^{[7]}$.

The additional role of CT in performing CT guided biopsies of lesions cannot be over emphasized. Since the advent of $\mathrm{CT}$, a decline in the use of other diagnostic chest procedures like chest fluoroscopy, mediastinoscopy, arteriography and thoracotomy has occurred. The skepticism and controversy that greeted the introduction of this expensive modality has gradually faded away.

\section{Methods}

The prospective study was carried out in tertiary centre from October 2010 - October 2012. This study for evaluating the efficacy of computed tomography in the diagnosis of mediastinal lesions was performed on 120 cases. Informed consent was taken from all patients.

All patients referred to Department of Radiodiagnosis with clinically suspected mediastinal space occupying lesions or with a chest radiogram with a suspicious mediastinal abnormality were being taken up for study.

Preprocedural workup consisted of the relevant clinical examination, routine hemogram, sputum examination and any other relevant investigation. 
Standard chest radiographs (Postero-Anterior and lateral views) and barium swallow investigation was done in cases where required.

The inclusion criteria were clinically suspected cases of mediastinal mass and in patients where the chest radiograph showed evidence of mediastinal mass lesion. Exclusion criteria were traumatic causes and cardiomegaly.

Pathological diagnosis was done by Fine Needle Aspiration Cytology (FNAC)/biopsy/surgery wherever it was required.

Computed tomography was done on SOMATOM EMOTION 6 SLICE (Siemens medical systems, Mumbai, India) CT scanner in all cases in supine position with breath hold at the end of inspiration. Contrast Enhanced Computed Tomography (CECT) was done using 60 to $120 \mathrm{ml}$ of $300 \mathrm{mg} / \mathrm{ml}$ of nonionic iodinated contrast (i.e. Ultravist/ Omnipaque).

CT scans of thorax were being viewed with slice acquisition thickness of $8 \mathrm{~mm}$ and reconstruction interval of $8 \mathrm{~mm}$ from the level of $2 \mathrm{~cm}$ superior to lung apices up to the diaphragm and routinely included the adrenals. Additional thin sections were being taken for multiplanar reconstructions and 3D image analysis.

CT scan images were being viewed in lung window (level $700 \mathrm{HU}$; width 1,500 HU), mediastinal window (level 30 HU-50 HU; width 350 HU-500 HU) and bone window (level 2,400 HU; width $200 \mathrm{HU}$ ).

CT scan analysis was done for any mediastinal mass, enhancement pattern, calcification, mass effect, bone destruction or associated findings (pulmonary/extra pulmonary/cardiac).

\section{Results}

As shown in Table 1 maximum numbers of cases (20\%) were seen in the age group of 51-60 years. There were 64 males and 56 females that give the ratio of 1.1:1. The difference in sex group was not significant.

Table 1. Distribution of patients examined according to age \& sex

\begin{tabular}{llll}
\hline Age group & Males & Females & $\%$ \\
\hline 0 to 10 & 2 & 0 & 1.67 \\
11 to 20 & 4 & 6 & 8.3 \\
21 to 30 & 6 & 4 & 8.3 \\
31 to 40 & 11 & 9 & 16.67 \\
41 to 50 & 9 & 7 & 13.3 \\
51 to 60 & 13 & 11 & 20 \\
61 to 70 & 12 & 10 & 18.3 \\
$>70$ & 7 & 9 & 13.3 \\
Total Cases & 64 & 56 & 100 \\
\hline
\end{tabular}

Anterior mediastinal masses formed the majority with 38.3\% $(n=46)$ of the total masses followed by posterior, middle and then superior constituting $16.67 \%(n=20), 13.3 \%(n=16)$ and $11.67 \%(n=14)$ respectively, as shown in Figure 1.

Twenty-four cases (20\%) showed masses in multiple compartments of mediastinum. Out of these 24 cases, 10 cases (41.6\%) involved both anterior and middle mediastinum, eight cases (33.3\%) involved both middle and posterior mediastinum and six cases (25\%) involved all compartments (anterior/middle/posterior) of mediastinum. The masses commonly found in multiple compartments were predominantly the lymph nodal masses due to carcinoma lung, lymphoma or tuberculosis. 
Superior mediastinal lesions comprised $11.67 \%(n=14)$ of the total mediastinal lesions. Out of 14 cases, 12 were thyroid masses constituting $85.7 \%(\mathrm{n}=12)$ and $14.3 \%(\mathrm{n}=2)$ cases were of lymphoma.

Figure 1. Compartmental distribution of mediastinal masses

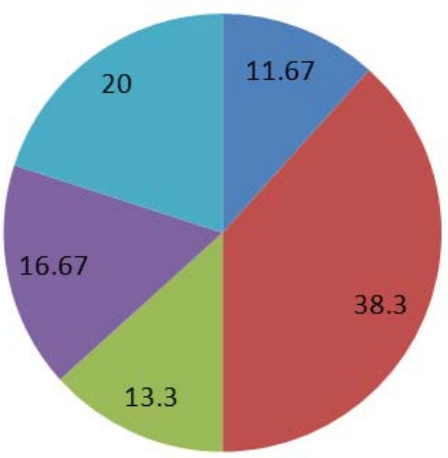

\author{
- Superior Mediastinum \\ Anterior Mediastinum \\ Middle Mediastinum \\ - Posterior Mediastinum \\ Multiple Compartments
}

Anterior mediastinal masses comprises predominantly of thymic lesions and metastatic lymph node constituting $26 \%$ $(\mathrm{n}=12)$ followed by ascending aortic aneurysm constituting $17.4 \%(\mathrm{n}=8)$.

Middle mediastinal lesions comprised $13 \%(\mathrm{n}=16)$ of the total mediastinal lesions. Among them the esophageal carcinoma formed the majority i.e. 37.5\% $(n=6)$ followed by non-tubercular infective/inflammatory lymph nodal enlargement comprising of $25 \%(n=4)$.

In the study, posterior mediastinal masses comprised $17 \%(n=20)$ of the total mediastinal masses, the majority of them were neural tumors constituting 50\% $(n=10)$ followed by hiatal hernia constituting 30\% $(n=6)$.

As seen in Table 2, majority of the mediastinal lesions/masses were solid constituting 50\% $(n=60)$ of the total masses followed by solid + cystic lesions constituting $26.7 \%(n=32)$ of the masses. $5.1 \%(n=6)$ masses which did not fall under any of above mentioned category were of hiatal hernia. Calcification was seen in only $33.3 \%(n=40)$ of cases.

Table 2. Distribution of the lesions based on their nature on CT

\begin{tabular}{lll}
\hline & No of Patients & \% \\
\hline Solid lesions & 60 & 50 \\
Solid + Cystic lesions & 32 & 26.7 \\
Cystic & 6 & 5.0 \\
Vascular lesions & 12 & 10 \\
Fatty + cystic + solid & 4 & 3.3 \\
None of the above & 6 & 5.0 \\
Total cases & 120 & 100 \\
\hline
\end{tabular}

Table 3 depicts that in present study majority of the lesions showed heterogeneous enhancement i.e. 58.3\% $(\mathrm{n}=70)$ followed by $15 \%(n=18)$ showed homogenous enhancement whereas $10 \%(n=12)$ lesions showed intense vascular enhancement on account of aortic aneurysm with/without dissection. $6.7 \%(\mathrm{n}=8)$ cases showed rim enhancement. Non enhancing masses and lesions showing luminal enhancement both constituted $5 \%(n=6)$ each.

In the study of 120 cases, 102 cases were histologically verified as shown by Table 4, six cases were hiatal hernia which were confirmed with endoscopy. In remaining 12 cases of vascular origin, a definitive diagnosis was established requiring no further evaluation. Table 5 shows the various mediastinal lesions diagnosed by CT and number of cases presented with each lesion. 
Table 3. CT enhancement pattern of mediastinal lesions

\begin{tabular}{lll}
\hline & No of Patients & \% \\
\hline Heterogeneous enhancement & 70 & 58.3 \\
Homogenous enhancement & 18 & 15 \\
Non enhancing lesions & 6 & 5 \\
Rim enhancement & 8 & 6.7 \\
Intense enhancement & 12 & 10 \\
Luminal enhancement & 6 & 5 \\
Total cases & 120 & 100 \\
\hline
\end{tabular}

Table 4. Correlation between CT and histopathological findings

\begin{tabular}{llll}
\hline Mediastinal Masses & Total & Histological & Non verifying \\
\hline Superior mediastinum & 14 & 14 & 0 \\
Anterior & 46 & 38 & 8 \\
Middle & 16 & 14 & 2 \\
Posterior & 20 & 12 & 8 \\
Multiple Compartments & 24 & 24 & 0 \\
\hline
\end{tabular}

Table 5. Diagnosis of the mediastinal lesions on the basis of CT findings

\begin{tabular}{lll}
\hline CT Diagnosis & No of Patients & \% \\
\hline Ascending aortic aneurysm & 8 & 6.7 \\
Aortic arch aneurysm & 2 & 1.7 \\
Bronchogenic cyst & 4 & 3.3 \\
Metastatic mediastinal LAP & 16 & 13.3 \\
Bronchogenic CA with mediastinal invasion & 4 & 3.3 \\
Descending thoracic aortic dissection & 2 & 1.7 \\
Esophageal carcinoma & 6 & 5 \\
Germ cell tumour & 4 & 3.3 \\
Hiatal hernia & 6 & 5 \\
LAP due to non tubercular infective/ inflammatory pathology & 4 & 3.3 \\
LAP due to lymphoma & 12 & 10 \\
Neurogenic tumour & 10 & 8.3 \\
Tubercular LAP & 18 & 15 \\
Thymoma & 10 & 8.3 \\
Thymic cyst & 2 & 1.7 \\
Thyroid masses & 12 & 10 \\
Total cases & 120 & 100 \\
\hline
\end{tabular}

\section{Discussion}

The mediastinum is the site for a vast range of diseases varying considerably i.e. tumors both benign and malignant, cysts, vascular lesions, lymph node masses and mediastinitis. Advent of CT has helped the clinicians and radiologists in identifying the precise location, extent and characterization of these masses.

In our study of 120 cases, patients which showed abnormal mediastinal shadow on radiographs or clinically suspected of involvement of the mediastinum were evaluated with computed tomography and correlated with pathological findings where possisble. 
In our study, the commonest symptom with which patient presented was cough $53 \%$ followed by dyspnoea $50 \%$, chest pain $20 \%$ and fever $17 \%$ whereas in the study of Davis et al. (1987) comprising of 400 consecutive patients with mediastinal masses, chest pain constituted the most common symptom i.e. in $30 \%$ followed by fever in $20 \%{ }^{[8]}$.

Anterior mediastinal lesions were the commonest accounting for 38.3\%. Posterior mediastinal lesions accounted for $16.67 \%$ of the cases followed by middle and then superior mediastinal lesions accounting for $13.3 \%$ and $11.67 \%$ respectively which is similar to the study conducted by Davis et al. ${ }^{[8]}$ on adults which depicted that anterior mediastinum constituted $54 \%$ of the masses followed by posterior and then middle which constituted $26 \%$ and $20 \%$ respectively. The findings of our study are also consistent with the study of Dubashi et al. ${ }^{[9]}$ which concluded that majority of tumors were seen in the anterior mediastinum followed by posterior mediastinum.

Twenty-four cases (20\%) showed masses in multiple compartments of mediastinum. Out these 24 cases, 10 cases (41.6\%) involved both anterior and middle mediastinum, eight cases (33\%) involved both middle and posterior mediastinum and six cases (25\%) involved all compartments (anterior/middle/posterior) of mediastinum. The masses commonly found in multiple compartments were predominantly the lymph nodal masses due to carcinoma lung, lymphoma or tuberculosis. Besides nodal masses, other lesions involving multiple compartments were bronchogenic cyst, bronchogenic carcinoma with mediastinal invasion.

Majority of mediastinal masses were benign lesions and seen most commonly in the age group of 31-40 years. 38.3\% ( $\mathrm{n}=$ 46) of the mediastinal masses were malignant and seen most commonly in the age group of 51-60 years i.e. sixth decade of life. Our study is in concordance with Karki S et al. ${ }^{[10]}$ who showed in a study of 27 cases with mediastinal lesions that 18 (66.6\%) cases were benign and seven (26\%) cases were malignant and two (7.4\%) cases were inconclusive.

In our study intrathoracic goiters represented $6.7 \%$ of mediastinal lesion which is in concordance with the studies of Khairy J et al. ${ }^{[11]}$ and Raffaelli M et al. ${ }^{[12]}$ which showed that the retrosternal goiters accounted for $3 \%-12 \%$ and $7 \%$ of mediastinal masses respectively. Majority of the patients of thyroid mass were females. Substernal goiters were seen arising on account of continuity of thyroid gland. Most of the patients experienced dyspnoea, dysphagia and cough. The findings are in concordance with the study of Katlic et al. ${ }^{[13]}$.

Thymic lesions constituted $10 \%$ of all mediastinal lesions while study by Davis et al. ${ }^{[8]}$ showed that thymic masses represented $17 \%$ of all mediastinal lesions. Among thymic lesions, thymoma constituted $83 \%$ which is similar to study conducted by Chen et al. ${ }^{[14]}$ that showed $91 \%$ of thymic masses to be thymoma on CT. Figures 2 and 3 shows the thymic masses as anterior mediastinal masses.

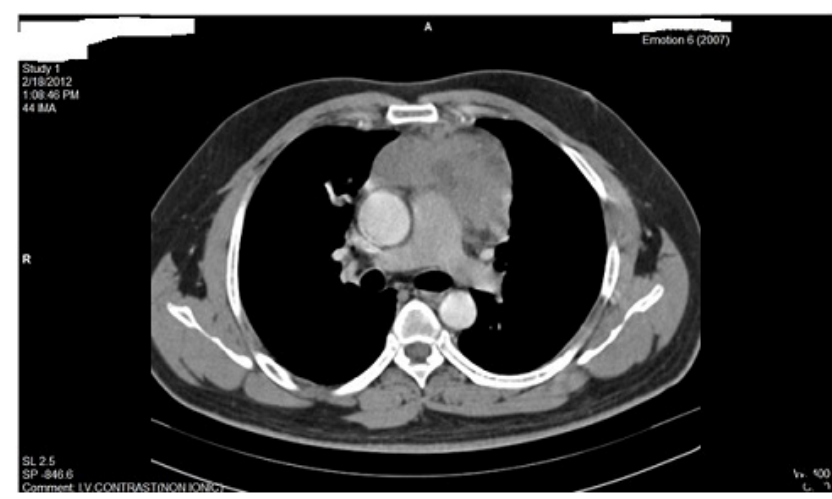

Figure 2. Coronal section-Benign thymic mass (Thymoma)

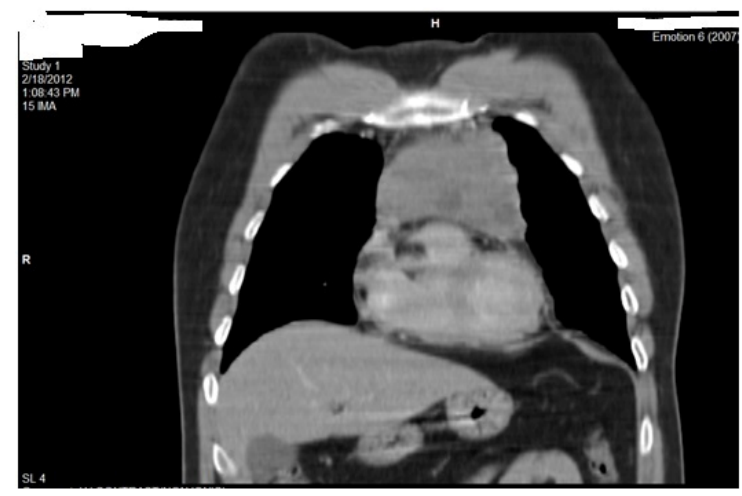

Figure 3. Axial Section-Benign thymic mass (Thymoma)

Lymphoma constituted $10 \%$ of the mediastinal masses (see Figure 4). Wychulis et al. ${ }^{[15]}$ in a study of 1,064 cases in 1971 found that lymphoma constituted $10.1 \%$ of the mediastinal masses which is in concordance of present study. 
Neurogenic tumors constituted 8.3\% ( $\mathrm{n}=10)$ of all mediastinal lesions and all $10(100 \%)$ were nerve sheath tumors which further comprised of $80 \%(n=8)$ schwannomas and $20 \%$ neurofibromas $(n=2)$. The findings are nearly similar to the study of Gale et al. ${ }^{[16]}$ which showed that schwannoma $(\mathrm{n}=46)$ was the most common lesion amongst the neurogenic tumors $(n=70)$.

Figure 4. Multiple mediastinal lymph nodes (Lymphoma)

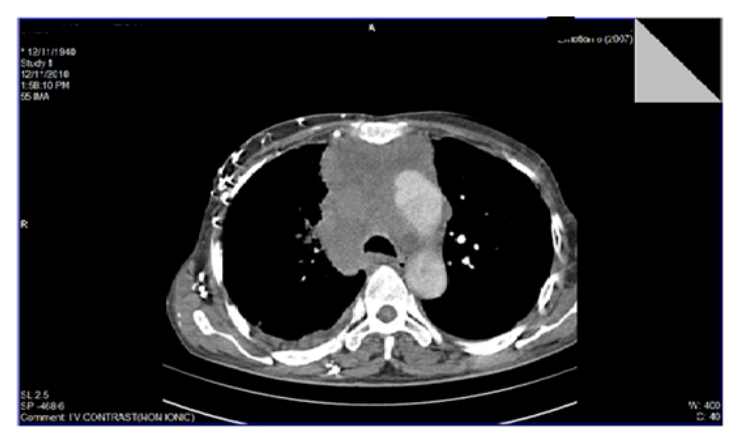

Tubercular granuloma constituted 33.3\%, which is greater in comparison to the study of Wychulis et al. (6.3\%) probably due to higher prevalence of tuberculosis in our country in comparison to the western population ${ }^{[15]}$. 55.5\% of cases with tubercular LAP showed central areas of low attenuation with rim enhancement (see Figure 5), which is comparable to the study of Im et al. ${ }^{[17]}$ depicting that 52\% of the tubercular lymph node enlargement showed central areas of low attenuation with rim enhancement on contrast study. Tubercular LAP was the commonest lesion in our study and constitutes $15 \%$ while thymic masses and neural tumors were the commonest mediastinal lesions in study conducted by Cohen et al. ${ }^{[18]}$ and Benjamin et al. ${ }^{[19]}$ respectively. The difference is probably due to different demographic profile and incidence of mediastinal masses in western studies, and non inclusion of secondaries and inflammatory lesions in above mentioned western studies which form a significant part of spectrum seen in developing countries.

Figure 5. Tubercular Lymphadenopathy in anterior and posterior mediastinum

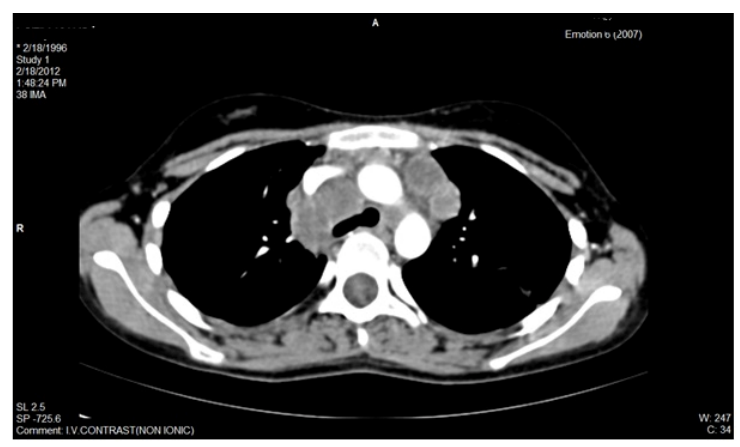

The ability of CT scan to distinguish specific tissue densities and to display mediastinum in axial plane makes it a useful technique in evaluating a widened mediastinum detected on conventional radiography. It is more appropriate to base the differential diagnosis of a mediastinal mass on direct observation of the tissue or structure from which the mass is arising (e.g., lymph nodes, veins, arteries, thymus, thyroid, esophagus etc.).

So we conclude that computed tomography definitely has a major role to play in the evaluation of a mediastinal mass regarding the organ of origin, distribution pattern, and extent of lesion, its density and mass effect upon adjacent structures.

\section{References}

[1] Shanks SL, Kerley P. Roentgen signs in clinical practice. Philadelphia: W. B. Saunders Company. 1962; 862-892.

[2] Pugatch RD, Faling LJ, Robins AH. Computerised Tomographic diagnosis of benign mediastinal abnormalities. AJR. 1980; 134: 685. PMid: 6767352. http://dx.doi.org/10.2214/ajr.134.4.685 
[3] Redina A, Munden RF, Pugatch RD, Liptay MJ. Computerised Tomographic staging of anterior mediastinal neoplasms. Thorax. 1988; 43: 441-45. http://dx.doi.org/10.1136/thx.43.6.441

[4] Crowe JK, Brown LR, Muhm JR. Computed Tomography of the Mediastinum. Radiology. 1978; 128: 75-87. PMid: 663229.

[5] Webb WR. Advances in computed tomography of the thorax. Radiol Clin North Am. 1983; 21(4): 723-29. PMid: 6657967.

[6] Baron RL, Levitt RG, Sagel SS, Stanley RJ. Computed tomography in the evaluation of mediastinal widening. Radiology. 1981; 138: 107-13. PMid: 7455069.

[7] Naidich DP, Webb WR, Muller NL, Zerhouni EA, Seigelmann SS. Computed tomography and Magnetic Resonance of the thorax. 3rd ed. Philadelphia: Lippincott Williams and Wilkins. 1999; 38-160.

[8] Davis RD, Oldham HN, Sabiston DC. Primary cysts and neoplasms of the mediastinum: Recent changes in clinical presentations, methods of diagnosis, management and results. Ann Thorac Surg. 1987; 44: 229-37. http://dx.doi.org/10.1016/S0003-4975(10)62059-0

[9] Dubashi B, Cyriac S, Tenali SG. Clinicopathological analysis and outcome of primary mediastinal malignancies. A report of 91 cases from a single institute. Ann Thorac. 2009; 4(3): 140-2. PMid: 19641646. http://dx.doi.org/10.4103/1817-1737.53354

[10] Karki S, Chalise S. Analysis of mediastinal lesions: a study of 27 cases. Journal of Pathology of Nepal. 2011; 1: 114-7. http://dx.doi.org/10.3126/jpn.v1i2.5404

[11] Khairy G, Alsaif A. Large Retrosternal Goitre: A Diagnostic and Treatment Dilemma. OMG. 2010; $25: 44$.

[12] Raffaelli M, Bellantone R, Princi P. Surgical treatment of thyroid diseases in elderly patients. American Journal of Surgery. 2010; 200(4): 467-72. PMid: 20887839. http://dx.doi.org/10.1016/j.amjsurg.2009.12.020

[13] Katlic MR, Wang C, Grillo HC. Substernal Goiter. Ann Thorac Surg. 1985; 39: 391-9. http://dx.doi.org/10.1016/S0003-4975(10)62645-8

[14] Chen J, Weisbrod GL, Herman SJ. Computed tomography and pathologic correlations of thymic lesion. J Thorac Imaging. 1988; 3: 61-5. PMid: 3336064. http://dx.doi.org/10.1097/00005382-198801000-00010

[15] Wychulis AR, Payne WS, Clagett OT, Woolner LB. Surgical treatment of mediastinal tumors: a 40 year experience. J Thorac Cardiovas Surg. 1971; 62: 379-92. PMid: 4331304.

[16] Gale AW, Jelihovsky T, Grant AF, Leckie BD, Nicks R. Neurogenic Tumors of the Mediastinum. Ann Thorac Surg. 1974; 17: 434-43. http://dx.doi.org/10.1016/S0003-4975(10)65676-7

[17] Im JG, Itoh H, Shim YS. Pulmonary Tuberculosis: CT findings early active disease and sequential change with antituberculous therapy. Radiology. 1993; 186: 653-60. PMid: 8430169.

[18] Cohen AJ, Thompson LN, Edwards FH, Bellamy RF. Primary cysts and tumors of the mediastinum. Ann Thorac Surg. 1991; 51: 378-86. http://dx.doi.org/10.1016/0003-4975(91)90848-K

[19] Benjamin SP, McCormack LJ, Effler DB. Primary tumors of the mediastinum. Chest. 1972; 62: 297-303. PMid: 4341427. http://dx.doi.org/10.1378/chest.62.3.297 